\title{
Comparative efficacy of $\mathrm{HgCl}_{2}$ with candidate aquaporin-1 inhibitors DMSO, gold, TEA+ and acetazolamide
}

\author{
Baoxue Yang ${ }^{\star}$, Jung Kyung Kim, and A.S. Verkman \\ Departments of Medicine and Physiology, Cardiovascular Research Institute, 1246 Health \\ Sciences East Tower, Box 0521, University of California, UCSF, San Francisco, CA 94143-0521, \\ USA
}

Baoxue Yang: byang@itsa.ucsf.edu

\begin{abstract}
Aquaporin-1 (AQP1) inhibitors are predicted to have multiple clinical applications. $\mathrm{Hg}^{++}$is a nonspecific and toxic AQP1 blocker. We compared compounds with reported AQP1 inhibition activity, including DMSO, $\mathrm{Au}^{+++}, \mathrm{Ag}^{+}$, tetraethylam-monium and acetazolamide. Water permeability was measured by stopped-flow light scattering in erythrocytes and volume marker dilution in epithelial cells. Au ${ }^{+++}$inhibited AQP1 with IC50 $14 \mu \mathrm{M}$, similar to $10 \mu \mathrm{M}$ for $\mathrm{Hg}^{++}$. DMSO slowed osmotic equilibration; however, the apparent inhibition was due to 'osmotic clamp' rather than AQP1 inhibition. Neither tetraethylammonium nor acetazolamide (to $10 \mathrm{mM}$ ) inhibited AQP1. Our data indicate the need to identify new AQP1 inhibitors. Published by Elsevier B.V. on behalf of the Federation of European Biochemical Societies.
\end{abstract}

\section{Keywords}

AQP1; Water transport; Water channel; Inhibitor; Drug discovery

\section{Introduction}

The aquaporins (AQPs) are a family of molecular water transporting proteins of molecular size $\sim 30 \mathrm{kDa}$ per monomer. There are $>10$ mammalian AQPs, which are expressed in cell plasma membranes of various epithelial, endothelial and other cell types [1-3]. AQP1 is an efficient water transporting protein that does not transport $\mathrm{H}^{+}$, urea or other small solutes $[4,5]$. It has been reported that $\mathrm{AQP1}$ may also transport $\mathrm{K}^{+}$and gases such as $\mathrm{CO}_{2}$ [6-9], though significant conflicting data exist [10-12]. AQP1 monomers are assembled in membranes as tetramers, though each monomer contains its own narrow pore for passage of water. High-resolution structural data $[13,14]$ indicate that AQP1 monomers contain six ahelical, membrane-spanning segments surrounding a narrow pore, with smaller domains that partially reside in the pore and confer water selectivity.

AQP1 is expressed in various epithelia (kidney proximal tubule, choroid plexus, ciliary body) and endothelia (microcapillaries, intestinal lacteals, lymphatics). Phenotype analysis of AQP1 knock-out mice indicate involvement of AQP1 in epithelial cell fluid absorption and secretion, angiogenesis and cell migration (reviewed in Ref. [1]). AQP1 null mice manifest defects in urinary concentrating ability $[15,16]$ and tumor angiogenesis [17], as well as reduced secretion of cerebrospinal fluid by the choroid plexus [18], and of aqueous

"Corresponding author. Fax: +14156653847.

Edited by Maurice Montal 
fluid by the ciliary epithelium [19]. Rare humans lacking functional AQP1 manifest a qualitatively similar urinary concentrating defect to mice [20]. The phenotype data provide compelling rationale for evaluation of AQP1 inhibitors as diuretics, and as anti-secretory and anti-angiogenic agents for potential therapy of congestive heart failure, hypertension, glaucoma, tumor growth and spread, and other disorders.

The best established water channel inhibitors are sulfhydrylreactive mercurials such as $\mathrm{HgCl}_{2}$; however, they are non-specific in their action and toxic to living cells. Mercurials inhibit AQP1 water permeability by covalent modification of cysteine-187 in the AQP1 sequence, as C187A and related AQP1 mutants are mercurial-insensitive [21,22]. As described in Section 4, a variety of other small molecules have been reported to inhibit $\mathrm{AQP1}$ water permeability, including $\mathrm{Au}^{+++}$and $\mathrm{Ag}^{+}$[23], tetraethylammonium $\left(\mathrm{TEA}^{+}\right.$) [24], acetazolamide [25] and DMSO [26]. Based on initial data showing DMSO inhibited water permeability in kidney vesicles [26], DMSO has been assumed to be a general inhibitor of AQP-facilitated water transport and hence DMSO inhibition has been taken to indicate AQP expression and function [27-31]. TEA ${ }^{+}$and acetazolamide have been proposed as lead candidates for clinical development [32,33]. The purpose of this study is to compare $\mathrm{Hg}^{++}$ with other candidate compounds for AQP1 inhibition potency and efficacy. For these studies we used two sensitive, complimentary assays of AQP1-facilitated water transport, involving native AQP1-expressing erythrocytes, and stably transfected AQP1-expressing epithelial cells.

\section{Material and methods}

\subsection{Erythrocytes and epithelial cell cultures}

Human venous blood was obtained from three donors. Blood was collected into Vacutainers coated with sodium heparin (Becton-Dickinson, Franklin Lakes, NJ). Mouse blood was collected from 8 to 12 week-old (25-35 g) wildtype or AQP1-null mice [15] in a CD1 genetic background by tail bleeding following subcutaneous injection with sodium heparin (150 USP units). Animal protocols were approved by the University of California, San Francisco Committee on Animal Research.

Fisher rat thyroid epithelial (FRT) cells stably expressing AQP1 [17] were grown in F12Coombs medium (Sigma-Aldrich, St. Louis, MO) supplemented with $10 \%$ fetal bovine serum (Hyclone), penicillin G (100 U/ml), streptomycin $(100 \mu \mathrm{g} / \mathrm{ml})$ and geneticin $(500 \mu \mathrm{g} /$ $\mathrm{ml}$ ) (antibiotic selection marker). For dye-dilution experiments, FRT cells were plated onto Transwell inserts (Corning Inc., Corning, NY) and used for flux measurements at resistances of $2-5 \mathrm{k} \Omega \mathrm{cm}^{2}$.

\subsection{Chemical and solutions}

DMSO, hydroxyurea, $\mathrm{HAuCl}_{4}\left(\mathrm{Au}^{+++}\right), \mathrm{AgNO}_{3}\left(\mathrm{Ag}^{+}\right), \mathrm{HgCl}_{2}\left(\mathrm{Hg}^{++}\right)$, tetraethylammonium $\left(\mathrm{TEA}^{+}\right)$, tetrapropylammonium $\left(\mathrm{TPrA}^{+}\right)$and acetazolamide were purchased from SigmaAldrich. Solutions were freshly prepared just before experiments. For experiments with $\mathrm{AgNO}_{3}$ all $\mathrm{Cl}^{-}$was replaced by $\mathrm{NO}_{3}^{-}$.

\subsection{Stopped-flow light scattering measurements}

Freshly obtained erythrocytes were washed three times in PBS to remove plasma and the cellular buffy coat. Stopped-flow measurements were done on a Hi-Tech Sf-51 instrument. Suspensions of erythrocytes ( $\sim .5 \%$ hematocrit) in PBS were subjected to a $250 \mathrm{mM}$ inwardly directed gradient of sucrose. The kinetics of decreasing cell volume was measured from the time course of $90^{\circ}$ scattered light intensity at $530 \mathrm{~nm}$ wavelength. Osmotic water permeability coefficients $\left(P_{\mathrm{f}}\right)$ were computed from the light scattering time course, as 
described [10]. In some experiments, DMSO, hydroxyurea, $\mathrm{Au}^{+++}, \mathrm{Ag}^{+}, \mathrm{TEA}^{+}, \mathrm{TPrA}^{+}$, acetazolamide or $\mathrm{Hg}^{++}$were added to the erythrocyte suspension and the hyperosmolar sucrose solution (500 $\mathrm{mM}$ sucrose in PBS) for $15 \mathrm{~min}$ (or up to $4 \mathrm{~h}$ ) before stopped-flow experiments.

For measurement of DMSO and hydroxyurea permeabilities, the erythrocyte suspension in PBS was subjected to a $250 \mathrm{mM}$ inwardly directed gradient of these solutes at $10^{\circ} \mathrm{C}$. The kinetics of decreasing cell volume was measured by light scattering as described above. Permeability coefficients $\left(P_{\mathrm{DMSO}}\right.$ and $\left.P_{\text {hydroxyurea }}\right)$ were computed from the relation: $P_{S}=1 /$ $[(S / V) \tau]$, where $S / V$ is surface-to-volume ratio and $\tau$ is the exponential time constant fitted to the cell swelling phase of the light scattering time course corresponding to solute entry.

\subsection{Transepithelial water permeability measurements}

Osmotic water permeabilities across FRT cell layers were determined using a dye dilution method, as described [34]. The dilution of a cell-impermeant, inert dye (Texas Red ${ }^{\mathrm{TM}}$ dextran, $10 \mathrm{kDa}$, Molecular Probes, Eugene, OR) was used as a measure of transcellular osmotic water flux. The basal surface of cells on a porous filter was bathed in $1 \mathrm{ml}$ of isosmolar PBS. The apical surface was bathed in $200 \mu$ l of hyperosmolar PBS (PBS + 300 $\mathrm{mM}$ D-mannitol) containing $0.25 \mathrm{mg} / \mathrm{ml}$ Texas Red-dextran. In some experiments, TEA ${ }^{+}$or acetazolamide (dissolved freshly from powder) was added to both the apical and basalbathing buffers. Five $\mu \mathrm{l}$ samples of dye-containing apical fluid was collected at specified times. Samples were diluted in $2 \mathrm{ml}$ of PBS and fluorescence was measured by cuvette fluorimetry (Fluoro Max-3, Horiba, Tokyo, Japan). Transepithelial osmotic water permeability coefficients $\left(P_{\mathrm{f}}\right.$ in $\left.\mathrm{cm} / \mathrm{s}\right)$ were computed from indicator dilution data, as described [34].

\subsection{Simulations of DMSO effect on osmotic equilibration}

Coupled osmotic water and solute transport across the erythrocyte plasma membrane was modeled using the flux equations: Water flux $-J_{\mathrm{v}}\left(\right.$ in $\left.\mathrm{cm}^{3} / \mathrm{s}\right)=-P_{\mathrm{f}} \cdot S \cdot v_{W} \cdot\left[\left(I_{\mathrm{e}}-I_{\mathcal{C}}(i)\right)+\right.$ $\left.\left(U_{\mathrm{e}}-U_{\mathrm{c}}(i)\right)\right]$; Solute flux $-J_{\mathrm{s}}($ in mol/s $)=P_{\mathrm{s}} \cdot S \cdot\left(U_{\mathrm{e}}-U_{\mathrm{c}}(i)\right)$. Permeability coefficients $\left(P_{\mathrm{f}}\right.$ and $P_{\mathrm{s}}$ ) are expressed in units of $\mathrm{cm} / \mathrm{s}$, cell surface area $(S)$ in $\mathrm{cm}^{2}$, extracellular (e) and cellular (c) concentrations of impermeant $(I)$ and permeant $(U)$ solute (DMSO) in mol $/ \mathrm{cm}^{3}$, and $v_{W}$ is $18 \mathrm{~mol} / \mathrm{cm}^{3}$. The equations were numerically integrated as described [35], assuming unity solute reflection coefficient. $P_{\mathrm{f}}$ and $P_{\mathrm{S}}\left(P_{\mathrm{DMSO}}\right.$ and $\left.P_{\text {hydroxyurea }}\right)$ were determined experimentally. Appropriate initial conditions were chosen to simulate effects of DMSO on the kinetics of $V(t)$, assumed to be related inversely to scattered light intensity.

\section{Results}

\subsection{Effect of putative AQP1 inhibitors on erythrocyte water permeability}

Putative inhibitors of AQP1 were screened at high concentration in erythrocytes from wildtype mice, including TEA ${ }^{+}$(and its analog $\operatorname{TPr}{ }^{+}$), heavy metal ions $\left(\mathrm{Hg}^{++}, \mathrm{Au}^{+++}\right.$and $\left.\mathrm{Ag}^{+}\right)$and acetazolamide. Measurements were done at low temperature $\left(10^{\circ} \mathrm{C}\right)$, where the strongly temperature-dependent lipid-mediated water permeability is minimized.

Erythrocyte osmotic equilibration was rapid $(\sim 250 \mathrm{~ms})$ in wildtype mice under control condition (Fig. 1A). At $100 \mu \mathrm{M}$, substantial inhibition was seen for $\mathrm{Hg}^{++}, \mathrm{Au}^{+++}$and $\mathrm{Ag}^{+}$, though no inhibition was seen for $\mathrm{TEA}^{+}, \mathrm{TPrA}^{+}$or acetazolamide. No significant effect of these compounds was seen in AQP1-null erythrocytes, where water permeability was greatly slowed, ruling out non-specific compound effects on AQP1-independent water transport (primarily through erythrocyte membrane lipids). Consistent with our previous results [36], mouse erythrocytes do not contain non-AQP1 mercurial-sensitive water channels. Averaged 
osmotic water permeability coefficients $\left(P_{\mathrm{f}}\right)$ are summarized in Fig. 1B, showing standard errors from 3 sets of studies, each done on blood from difference mice.

Concentration-inhibition data is summarized in Fig. 2. Comparable, near-complete inhibition of water transport was found for higher concentrations of $\mathrm{Hg}^{++}, \mathrm{Au}^{+++}$and $\mathrm{Ag}^{+}$, with IC50 values of approximately 10,14 and $6 \mu \mathrm{M}$, respectively. No significant inhibition was seen for $\mathrm{TEA}^{+}, \mathrm{TPrA}^{+}$(each $10 \mathrm{mM}$ ) or acetazolamide ( 2mM, solubility limit) (Fig. 2) even after incubation with erythrocytes for 1 and $4 \mathrm{~h}$ (not shown).

Because no inhibition was found for $\mathrm{TEA}^{+}, \mathrm{TPrA}^{+}$or acetazolamide in mouse erythrocytes, measurements were done on human erythrocytes and on AQP1-expressing epithelial cells. As is well-known, $P_{\mathrm{f}}$ is lower in human than in mouse erythrocytes. $\mathrm{Au}^{+++}, \mathrm{Ag}^{+}$and $\mathrm{Hg}^{++}$ strongly reduced water permeability in human erythrocytes when measured at $10{ }^{\circ} \mathrm{C}$ (Fig. $3 \mathrm{~A})$ or $23^{\circ} \mathrm{C}$ (Fig. 3B). No significant inhibition was found for $\mathrm{TEA}^{+}, \mathrm{TPrA}^{+}$or acetazolamide.

\subsection{Transepithelial water permeability in AQP1-expressing FRT cells}

Measurements of transepithelial water permeability were done in AQP1-expressing FRT epithelial cells using a dye dilution method. The fluorescence of an apical solution volume marker provided a quantitative readout of osmotically driven water transport across the cell layer. Transepithelial $P_{\mathrm{f}}$ was deduced from the kinetics of dye dilution in response to a 300 $\mathrm{mM}$ gradient of mannitol to induce basolateral-to-apical osmotic water flux. Dye dilution was much faster in AQP1-expressing vs. control (non-transfected) FRT cells, with no significant difference seen in AQP1-expressing cells that were pre-treated for 15 min with 1 $\mathrm{mM} \mathrm{TEA}^{+}$or acetazolamide (Fig. 4A). Fig. 4B summarizes transepithelial $P_{\mathrm{f}}$ values.

\subsection{DMSO slows osmotic equilibration but is not an AQP1 inhibitor}

DMSO (0-2\% wt/vol) was tested as an inhibitor of erythrocyte water permeability by addition to the erythrocyte suspension and the hyperosmolar sucrose solution prior to stopped-flow measurements. Similar to prior data on kidney vesicles [26], DMSO produced a concentration-dependent reduction in the apparent rate of osmotic equilibration (Fig. 5A), as seen best from the slowed equilibration at long times. To compute absolute (corrected) $P_{\mathrm{f}}$, the Kedem-Katchalsky equations for coupled water/solute flow were numerically integrated using a DMSO permeability coefficient (PDMSO) of $1.5 \times 10^{-6} \mathrm{~cm} / \mathrm{s}$, as measured by stopped-flow light scattering (Fig. 5B, top). Fig. 5C shows simulated stopped-flow kinetics computed with constant erythrocyte $P_{\mathrm{f}}$. DMSO was predicted to produce apparent slowing of osmotic equilibration, as found experimentally. These computations suggest that DMSO is not a bona fide AQP1 inhibitor - that slowing of osmotic equilibration is a consequence of its high osmolality and transport rate ('osmotic-clamp' effect).

As further evidence that DMSO is not an AQP1 inhibitor, we screened a series of small solutes to identify a solute with permeability similar to that of DMSO. As shown in Fig. 5B (bottom), hydroxyurea has near identical permeability to DMSO. Fig. 5D shows stoppedflow light scattering measurements done as in Fig. 5A, except for hydroxyurea in place of DMSO. The apparent inhibition of erythrocyte osmotic water equilibration by hydroxyurea was nearly identical to that for DMSO, supporting the conclusion that DMSO is not an AQP1 inhibitor.

\section{Discussion}

The purpose of this study was to evaluate the efficacy and potency of several unrelated compounds that have been reported as AQP1 inhibitors. Our data confirmed AQP1 inhibition by the metal ions $\mathrm{Ag}^{+}$and $\mathrm{Au}^{+++}$, as reported [23], in agreement with the older 
literature showing water channel inhibition by $\mathrm{Hg}^{++}$and various other heavy metal ions [3739]. Although $\mathrm{Au}^{+++}$and $\mathrm{Ag}^{+}$effectively inhibited AQP1 water permeability, they are not useful for development as clinically useful AQP1 inhibitors because they are predicted to be non-specific in their action. $\mathrm{Ag}^{+}$is insoluble in physiological $\mathrm{Cl}^{-}$-containing solutions, and $\mathrm{Au}^{+++}$would be toxic at concentrations needed to inhibit AQP1 water permeability. DMSO was confirmed to slow osmotic equilibration, as found many years ago [26], though its mechanism-of-action was determined to involve 'osmotic-clamp' rather than direct AQP1 inhibition. We found no significant inhibition of AQP1 by TEA ${ }^{+}$or acetazolamide, which contradicts prior results.

DMSO was first proposed to be a water transport inhibitor in stopped-flow light scattering measurements on renal proximal tubule vesicles [26], where water moves primarily through AQP1. However, the conclusion that DMSO inhibited water permeability was based on an incorrect interpretation that reduced amplitude (rather than altered kinetics) of their light scattering data in terms of water transport inhibition. Reduced signal amplitude likely represents a combination of DMSO osmotic effect, which lessens vesicle volume change, and DMSO-increased solution refractive index, which reduces light scattering intensity. DMSO then acquired the unjustified reputation as a general AQP water transport blocker, and subsequent papers have taken DMSO inhibition of osmotic equilibration as evidence for AQP-facilitated water transport. Our findings here indicate that DMSO slowing of osmotic water equilibration is a predictable effect of its significant osmolality and rapid membrane permeation. Similar slowing of osmotic equilibration was predicted and found for an unrelated small solute, hydroxyurea, which has similar molecular size and membrane permeability to DMSO. The extent of slowing of osmotic equilibration depends on membrane water and DMSO permeabilities, and DMSO concentration. The predicted lesser effect of DMSO on osmotic water equilibration when water permeability is low probably accounts, in part, for the erroneous conclusion that DMSO is a general AQP inhibitor. We conclude that apparent inhibition of water transport by high millimolar concentrations of DMSO or other small, uncharged solutes cannot be taken as evidence for functional AQP expression.

$\mathrm{TEA}^{+}$is a well-known pore-occluding blocker of voltagegated potassium channels [40,41]. The Yool lab first reported TEA ${ }^{+}$inhibition of AQP1. TEA ${ }^{+}$at $100 \mu \mathrm{M}$ inhibited water permeability of heterologously expressed human AQP1 in Xenopus oocytes by $>20 \%$, increasing to nearly $40 \%$ by $10 \mathrm{mM}$ [24]. In a follow-up study Yool et al. [42] reported 30$40 \%$ inhibition of water transport by $10 \mathrm{mM} \mathrm{TEA}^{+}$in AQP1-expressing MDCK cells and perfused thin descending limbs of Henle (TDLH) from rat kidney. Detmers et al. [33] also measured water permeability in AQP1-expressing Xenopus oocytes, reporting 40\% inhibition of water permeability by $100 \mu \mathrm{M} \mathrm{TEA}^{+}$and lesser inhibition by several TEA ${ }^{+}$ analogs. TEA ${ }^{+}$inhibition of water permeability was found for other AQPs as well, and $\mathrm{TEA}^{+}$inhibition of AQP1 water permeability was reduced after mutagenesis of some single residues.

We cannot account for the differences in the data here with those of the previous reports. Perhaps oocytes contain a $\mathrm{TEA}^{+}$-sensitive membrane protein or lipid component that interacts with AQP1. However, the study of Yool et al. [42] in TDLH could not be explained by oocyte-specific factor(s), though the reported TDLH data was associated with large statistical variability. Also, apparent water transport may be influenced by non-specific effects of the high $(10 \mathrm{mM}) \mathrm{TEA}^{+}$concentrations such as block of $\mathrm{K}^{+}$channels and consequent altered basal cell volume. Our data show that TEA ${ }^{+}$does not inhibit AQP1 water permeability in erythrocytes or AQP1-expressing epithelial cells at concentrations up to 10 $\mathrm{mM}$, under assay conditions in which $<10 \%$ inhibition would be easily detectable. The erythrocyte stopped-flow and transepithelial water permeability measurements have 
substantially less variation than oocyte water permeability measurements. We conclude that $\mathrm{TEA}^{+}$is not a robust inhibitor of mouse or human AQP1, and therefore not a 'lead compound' for clinical development.

The sulfanilamide carbonic anhydrase inhibitor acetazolamide was reported by Ma et al. [25] to inhibit water permeability by $>80 \%$ at $10 \mu \mathrm{M}$ in Xenopus oocytes, with IC50 1 $\mu \mathrm{M}$. A follow-up study from the same group [32] reported $\sim 40 \%$ inhibition of water permeability by $100 \mu \mathrm{M}$ acetazolamide in transfected HEK cells. They reported evidence by surface plasmon resonance of a possible direct interaction between AQP1 and acetazolamide that could account for the inhibition. Other somewhat conflicting data from the same group showed acetazolamide inhibited AQP1 protein expression, angiogenesis and tumor metastasis $[43,44]$. Here, we found no inhibition of AQP1 water transport in erythrocytes or AQP1-expressing epithelial cells at concentrations of acetazolamide up to $2 \mathrm{mM}$. We believe that studies from the Li group suggesting that acetazolamide is an AQP1 downregulator and inhibitor are flawed in their design and interpretation.

In summary, our data confirm the inhibition of AQP1 by the heavy metal ions $\mathrm{Au}^{+++}$and $\mathrm{Ag}^{+}$, but do not support the conclusions that TEA ${ }^{+}$or acetazolamide inhibit AQP1, or that DMSO is a general AQP inhibitor. Because of the multiple potential clinical indications of AQP1 inhibitors as mentioned in the introduction, our results underscore the need for smallmolecule discovery efforts to identify non-toxic, AQP1-selective inhibitors suitable for clinical use.

\section{Acknowledgments}

This work was supported by Grants DK35124, HL59198, EY13574, EB00415, DK72517, and HL73856 (to ASV) and DK66194 (to BY) from the National Institutes of Health, and a Research Development Program grant (R613) from the Cystic Fibrosis Foundation (to ASV).

\section{References}

1. Verkman AS. More than just water channels: unexpected cellular roles of aquaporins. J Cell Sci. 2005; 118:3225-3232. [PubMed: 16079275]

2. Agre P, King LS, Yasui M, Guggino WB, Ottersen OP, Fujiyoshi Y, Engel A, Nielsen S. Aquaporin water channels - from atomic structure to clinical medicine. J Physiol. 2002; 542:3-16. [PubMed: 12096044]

3. Ishibashi K, Kuwahara M, Sasaki S. Molecular biology of aquaporins. Rev Physiol Biochem Pharmacol. 2000; 141:1-32. [PubMed: 10916422]

4. Verkman AS, Mitra AK. Structure and function of aquaporin water channels. Am J Physiol. 2000; 278:F13-F28.

5. Heymann JB, Agre P, Engel A. Progress on the structure and function of aquaporin 1. J Struct Biol. 1998; 121:191-206. [PubMed: 9615438]

6. Yool AJ, Stamer WD, Regan JW. Forskolin stimulation of water and cation permeability in aquaporin 1 water channels. Science. 1996; 273:1216-1218. [PubMed: 8703053]

7. Nakhoul NL, Davis BA, Romero MF, Boron WF. Effect of expressing the water channel aquaporin-1 on the $\mathrm{CO}_{2}$ permeability of Xenopus oocytes. Am J Physiol. 1998; 274:C543-C548. [PubMed: 9486145]

8. Endeward V, Musa-Aziz R, Cooper GJ, Chen LM, Pelletier MF, Virkki LV, Supuran T, King LS, Boron WF, Gros G. Evidence that aquaporin 1 is a major pathway for $\mathrm{CO}_{2}$ transport across the human erythrocyte membrane. Faseb J. 2006; 20:1974-1981. [PubMed: 17012249]

9. Prasad GV, Coury LA, Finn F, Zeidel ML. Reconstituted aquaporin 1 water channels transport $\mathrm{CO}_{2}$ across membranes. J Biol Chem. 1998; 273:33123-33126. [PubMed: 9837877] 
10. Yang B, Fukuda N, van Hoek A, Matthay MA, Ma T, Verkman AS. Carbon dioxide permeability of aquaporin-1 measured in erythrocytes and lung of aquaporin-1 null mice and in reconstituted proteoliposomes. J Biol Chem. 2000; 275:2686-2692. [PubMed: 10644730]

11. Tsunoda SP, Wiesner B, Lorenz D, Rosenthal W, Pohl P. Aquaporin-1, nothing but a water channel. J Biol Chem. 2004; 279:11364-11367. [PubMed: 14701836]

12. Agre P, Lee MD, Devidas S, Guggino WB. Aquaporins and ion conductance. Science. 1997; 275:1490. [PubMed: 9045617]

13. Sui H, Han BG, Lee JK, Walian P, Jap BK. Structural basis of water-specific transport through the AQP1 water channel. Nature. 2001; 414:872-878. [PubMed: 11780053]

14. Fujiyoshi Y, Mitsuoka K, de Groot BL, Philippsen A, Grubmuller H, Agre P, Engel A. Structure and function of water channels. Curr Opin Struct Biol. 2002; 12:509-515. [PubMed: 12163075]

15. Ma T, Yang B, Gillespie A, Carlson EJ, Epstein CJ, Verkman AS. Severely impaired urinary concentrating ability in transgenic mice lacking aquaporin-1 water channels. J Biol Chem. 1998; 273:4296-4299. [PubMed: 9468475]

16. Schnermann J, Chou CL, Ma T, Traynor T, Knepper MA, Verkman AS. Defective proximal tubular fluid reabsorption in transgenic aquaporin-1 null mice. Proc Natl Acad Sci USA. 1998; 95:9660-9664. [PubMed: 9689137]

17. Saadoun S, Papadopoulos MC, Hara-Chikuma M, Verkman AS. Impairment of angiogenesis and cell migration by targeted aquaporin-1 gene disruption. Nature. 2005; 434:786-792. [PubMed: 15815633]

18. Oshio K, Watanabe H, Song Y, Verkman AS, Manley GT. Reduced cerebrospinal fluid production and intracranial pressure in mice lacking choroid plexus water channel aquaporin-1. Faseb J. 2005; 19:76-78. [PubMed: 15533949]

19. Zhang D, Vetrivel L, Verkman AS. Aquaporin deletion in mice reduces intraocular pressure and aqueous fluid production. J Gen Physiol. 2002; 119:561-569. [PubMed: 12034763]

20. King LS, Choi M, Fernandez PC, Cartron JP, Agre P. Defective urinary-concentrating ability due to a complete deficiency of aquaporin-1. N Engl J Med. 2001; 345:175-179. [PubMed: 11463012]

21. Zhang R, van Hoek AN, Biwersi J, Verkman AS. A point mutation at cysteine 189 blocks the water permeability of rat kidney water channel CHIP28k. Biochemistry. 1993; 32:2938-2941. [PubMed: 8457558]

22. Preston GM, Jung JS, Guggino WB, Agre P. The mercury-sensitive residue at cysteine 189 in the CHIP28 water channel. J Biol Chem. 1993; 268:17-20. [PubMed: 7677994]

23. Niemietz CM, Tyerman SD. New potent inhibitors of aquaporins: silver and gold compounds inhibit aquaporins of plant and human origin. FEBS Lett. 2002; 531:443-447. [PubMed: 12435590]

24. Brooks HL, Regan JW, Yool AJ. Inhibition of aquaporin-1 water permeability by tetraethylammonium: involvement of the loop E pore region. Mol Pharmacol. 2000; 57:10211026. [PubMed: 10779387]

25. Ma B, Xiang Y, Mu SM, Li T, Yu HM, Li XJ. Effects of acetazolamide and anordiol on osmotic water permeability in AQP1-cRNA injected Xenopus oocyte. Acta Pharmacol Sin. 2004; 25:90 97. [PubMed: 14704128]

26. van Hoek AN, de Jong MD, van Os CH. Effects of dimethylsulfoxide and mercurial sulfhydryl reagents on water and solute permeability of rat kidney brush border membranes. Biochim Biophys Acta. 1990; 1030:203-210. [PubMed: 2175653]

27. Moshelion M, Becker D, Biela A, Uehlein N, Hedrich R, Otto B, Levi H, Moran N, Kaldenhoff R. Plasma membrane aquaporins in the motor cells of Samanea saman: diurnal and circadian regulation. Plant Cell. 2002; 14:727-739. [PubMed: 11910017]

28. Marinelli RA, Tietz PS, Caride AJ, Huang BQ, LaRusso NF. Water transporting properties of hepatocyte basolateral and canalicular plasma membrane domains. J Biol Chem. 2003; 278:43157-43162. [PubMed: 12939275]

29. Cova E, Gong A, Marinelli RA, LaRusso NF. Water movement across rat bile duct units is transcellular and channel-mediated. Hepatology. 2001; 34:456-463. [PubMed: 11526529]

30. Dempster JA, van Hoek AN, de Jong MD, van Os CH. Glucose transporters do not serve as water channels in renal and intestinal epithelia. Pfugers Arch. 1991; 419:249-255. 
31. García F, Kierbel A, Larocca MC, Gradilone SA, Splinter P, LaRusso NF, Marinelli RA. The water channel aquaporin- 8 is mainly intracellular in rat hepatocytes, and its plasma membrane insertion is stimulated by cyclic AMP. J Biol Chem. 2001; 276:12147-12152. [PubMed: 11278499]

32. Gao J, Wang X, Chang Y, Zhang J, Song Q, Yu H, Li X. Acetazolamide inhibits osmotic water permeability by interaction with aquaporin-1. Anal Biochem. 2006; 350:165-170. [PubMed: 16480680]

33. Detmers FJ, de Groot BL, Muller EM, Hinton A, Konings IB, Sze M, Flitsch SL, Grubmuller H, Deen PM. Quaternary ammonium compounds as water channel blockers. Specificity, potency, and site of action. J Biol Chem. 2006; 281:14207-14214. [PubMed: 16551622]

34. Levin MH, Sullivan S, Nielson D, Yang B, Finkbeiner WE, Verkman AS. Hypertonic saline therapy in cystic fibrosis: evidence against the proposed mechanism involving aquaporins. J Biol Chem. 2006; 281:25803-25812. [PubMed: 16829520]

35. Levin MH, de la Fuente R, Verkman AS. Urearetics - nanomolar potency small-molecule urea transport inhibitors as novel diuretics. FASEB J. in press.

36. Yang B, Ma T, Verkman AS. Erythrocyte water permeability and renal function in double knockout mice lacking aquaporin-1 and aquaporin-3. J Biol Chem. 2001; 276:624-628. [PubMed: 11035042]

37. Parisi M, Piccinni ZF. Regulation of the permeability to water in toad urinary bladder: the effect of copper. J Endocrinol. 1972; 55:1-9. [PubMed: 4350080]

38. Hoch BS, Gorfien PC, Eres A, Shahmehdi S, Lipner HI. Comparative effect of metals on antidiuretic hormone induced transport in toad bladder: specificity of mercuric inhibition of water channels. Biometals. 1992; 5:95-101. [PubMed: 1525481]

39. Benga G. Water channels in membranes. Cell Biol Int. 1994; 18:829-833. [PubMed: 7528593]

40. Latorre R, Vergara C, Hidalgo C. Reconstitution in planar lipid bilayers of a $\mathrm{Ca}^{2+}$-dependent $\mathrm{K}^{+}$ channel from transverse tubule membranes isolated from rabbit skeletal muscle. Proc Natl Acad Sci USA. 1982; 79:805-809. [PubMed: 6278496]

41. Lang DG, Ritchie AK. Tetraethylammonium blockade of apamin-sensitive and insensitive $\mathrm{Ca}^{2+}$ activated $\mathrm{K}^{+}$channels in a pituitary cell line. J Physiol. 1990; 425:117-132. [PubMed: 1698974]

42. Yool AJ, Brokl OH, Pannabecker TL, Dantzler WH, Stamer WD. Tetraethylammonium block of water flux in aquaporin-1 channels expressed in kidney thin limbs of Henle's loop and a kidneyderived cell line. BMC Physiol. 2002; 2:4. [PubMed: 11914159]

43. Xiang Y, Ma B, Li T, Gao JW, Yu HM, Li XJ. Acetazolamide inhibits aquaporin-1 protein expression and angiogenesis. Acta Pharmacol Sin. 2004; 25:812-816. [PubMed: 15169637]

44. Xiang Y, Ma B, Li T, Yu HM, Li XJ. Acetazolamide suppresses tumor metastasis and related protein expression in mice bearing Lewis lung carcinoma. Acta Pharmacol Sin. 2002; 23:745-751. [PubMed: 12147198] 
A

A $+1+$

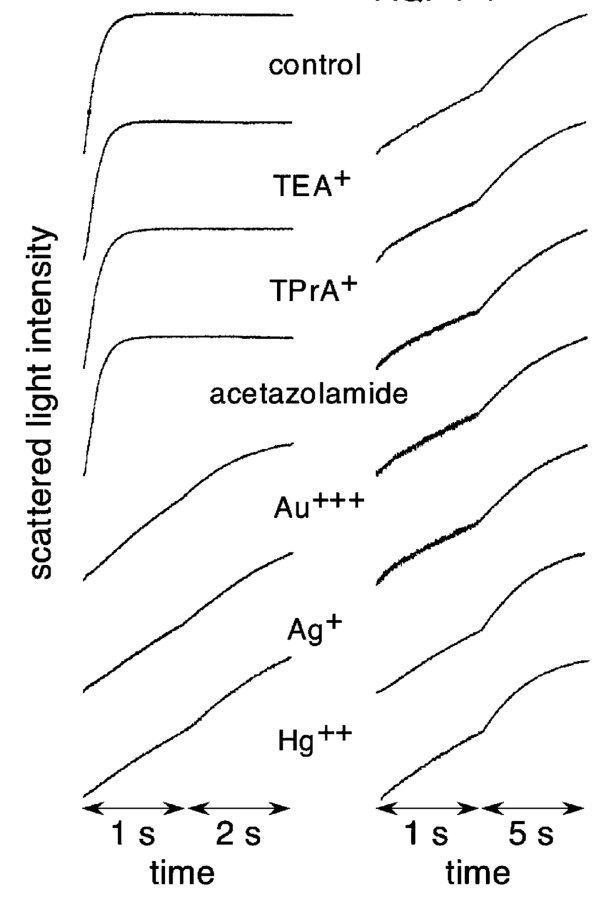

B

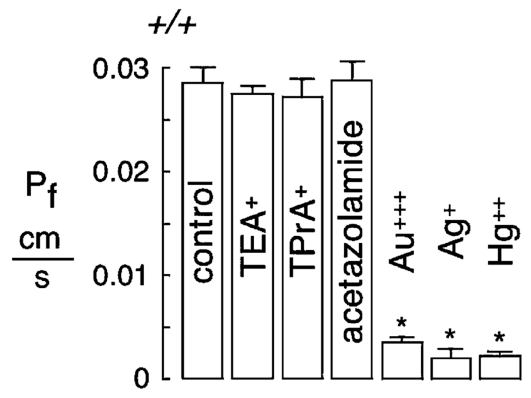

$A Q P 1-/-$

Fig. 1.

Osmotic water permeability in mouse erythrocytes measured by stopped-flow light scattering. Osmotic water permeability was measured from the time course of scattered light intensity in response to a $250 \mathrm{mM}$ inwardly directed sucrose gradient. (A) Measurements in erythrocytes from wildtype and AQP1 null mice done at $10{ }^{\circ} \mathrm{C}$ under control conditions (top curves) and in the presence of indicated inhibitors (each $100 \mu \mathrm{M}$ ). Erythrocytes were incubated with test compounds for 15 min before measurements. Activities of TEA ${ }^{+}$for $\mathrm{K}^{+}$ channel inhibition and of acetazolamide for carbonic anhydrase inhibition were confirmed. (B) Averaged osmotic water permeability coefficients $\left(P_{\mathrm{f}}\right)$ for experiments as in (A) done in erythrocytes from wildtype mice (top) and AQP1 null mice (bottom) (means \pm S.E., 3 mice of each genotype, 8 separate measurements per mouse). $* P<0.01$ compared to control. 


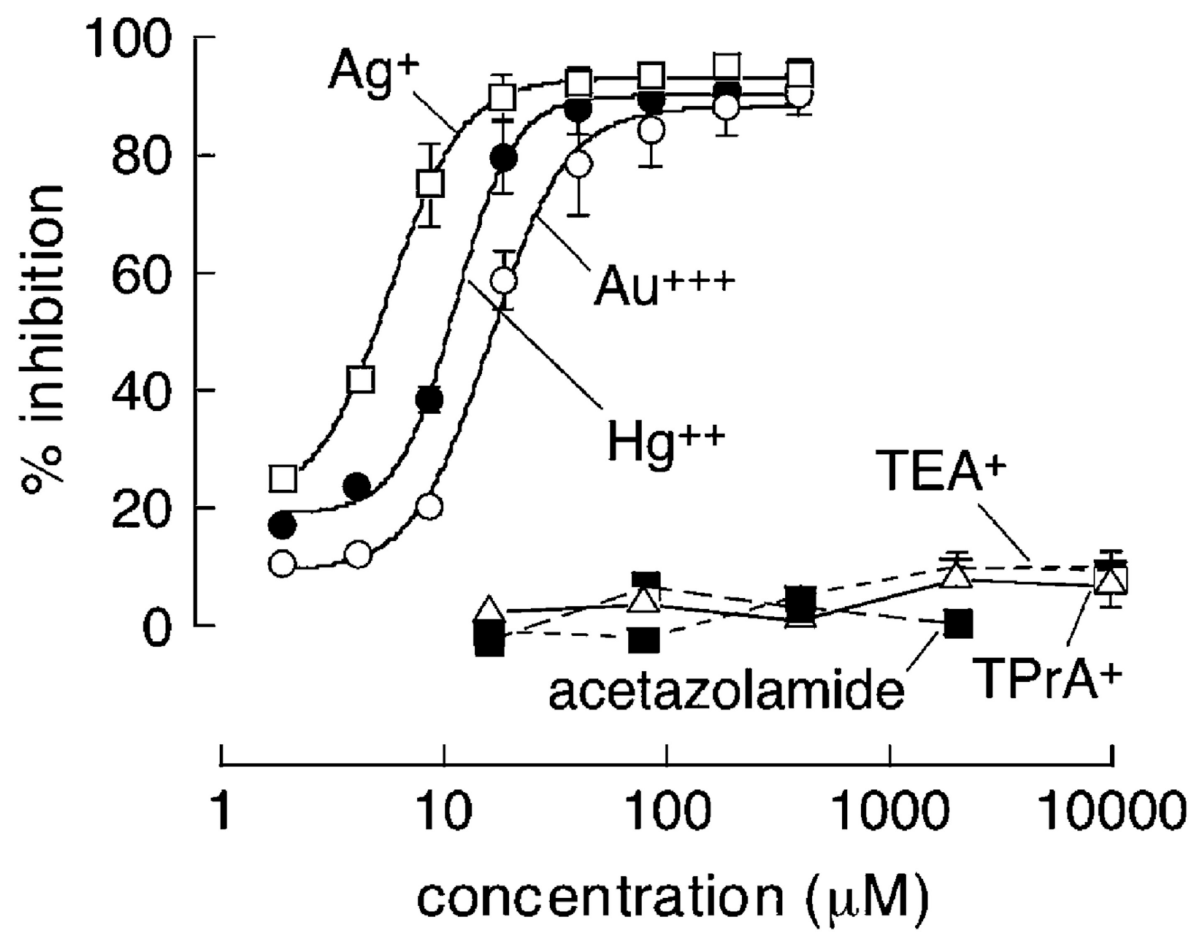

Fig. 2.

Concentration-inhibition analysis for water transport inhibition in erythrocytes from wildtype mice. Experiments done as in Fig. 1. Each point is means \pm S.E. (8 measurements) with fitted single-site inhibition curve shown. 

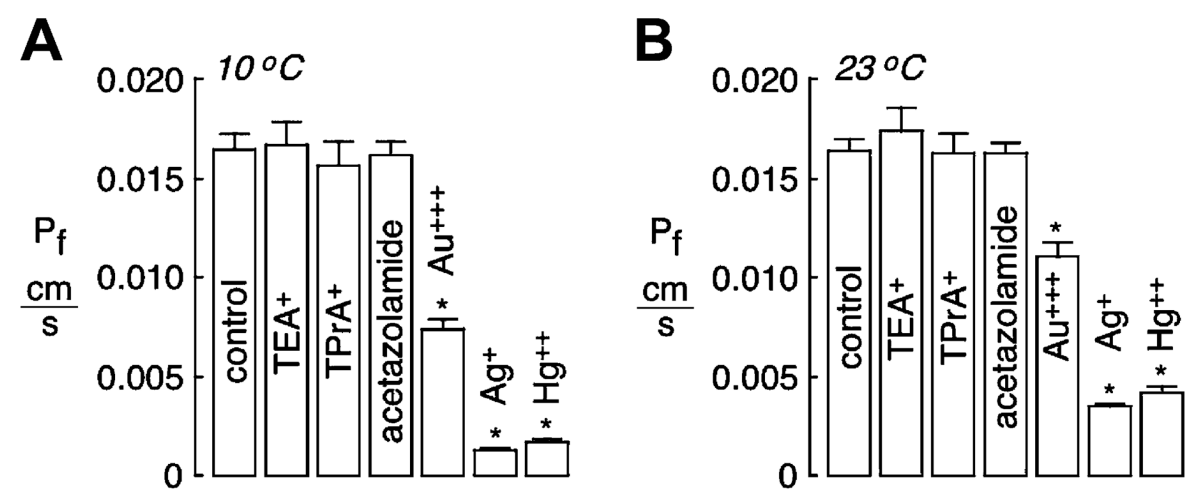

Fig. 3.

Osmotic water permeability in human erythrocytes measured by stopped-flow light scattering. Experiments done as in Fig. 1, but in human erythrocytes. (A) Averaged osmotic water permeability coefficients $\left(P_{\mathrm{f}}\right)$ (means \pm S.E., $\left.n=8\right)$ measured at $10^{\circ} \mathrm{C}$. (B) $P_{\mathrm{f}}$ measured at $23{ }^{\circ} \mathrm{C}$. $* P<0.01$ compared to control. 

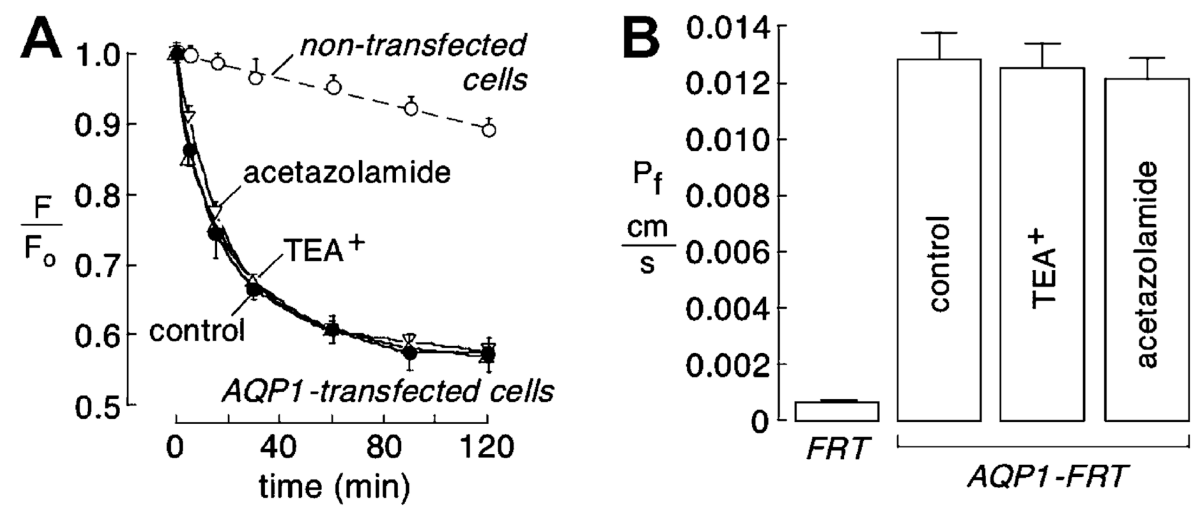

Fig. 4.

Transepithelial osmotic water permeability in AQP1-transfected FRT cell cultures. Water permeability of control and AQP1-expressing FRT cells at $23{ }^{\circ} \mathrm{C}$ measured by dye dilution as described under Materials and Methods. (A) Kinetics of dye dilution in control (nontransfected) FRT cells (open circles) and AQP1-expressing FRT cells (closed circles). Cells were incubated with $1 \mathrm{mM} \mathrm{TEA}{ }^{+}$or $1 \mathrm{mM}$ acetazolamide as indicated. Each point is means \pm S.E. for 3 experiments. Single-exponential fits shown as solid lines. (B) Summary of $P_{\mathrm{f}}$ values. Differences in AQP1-transfected FRT cells with $\mathrm{TEA}^{+}$and acetazolamide not significant. 

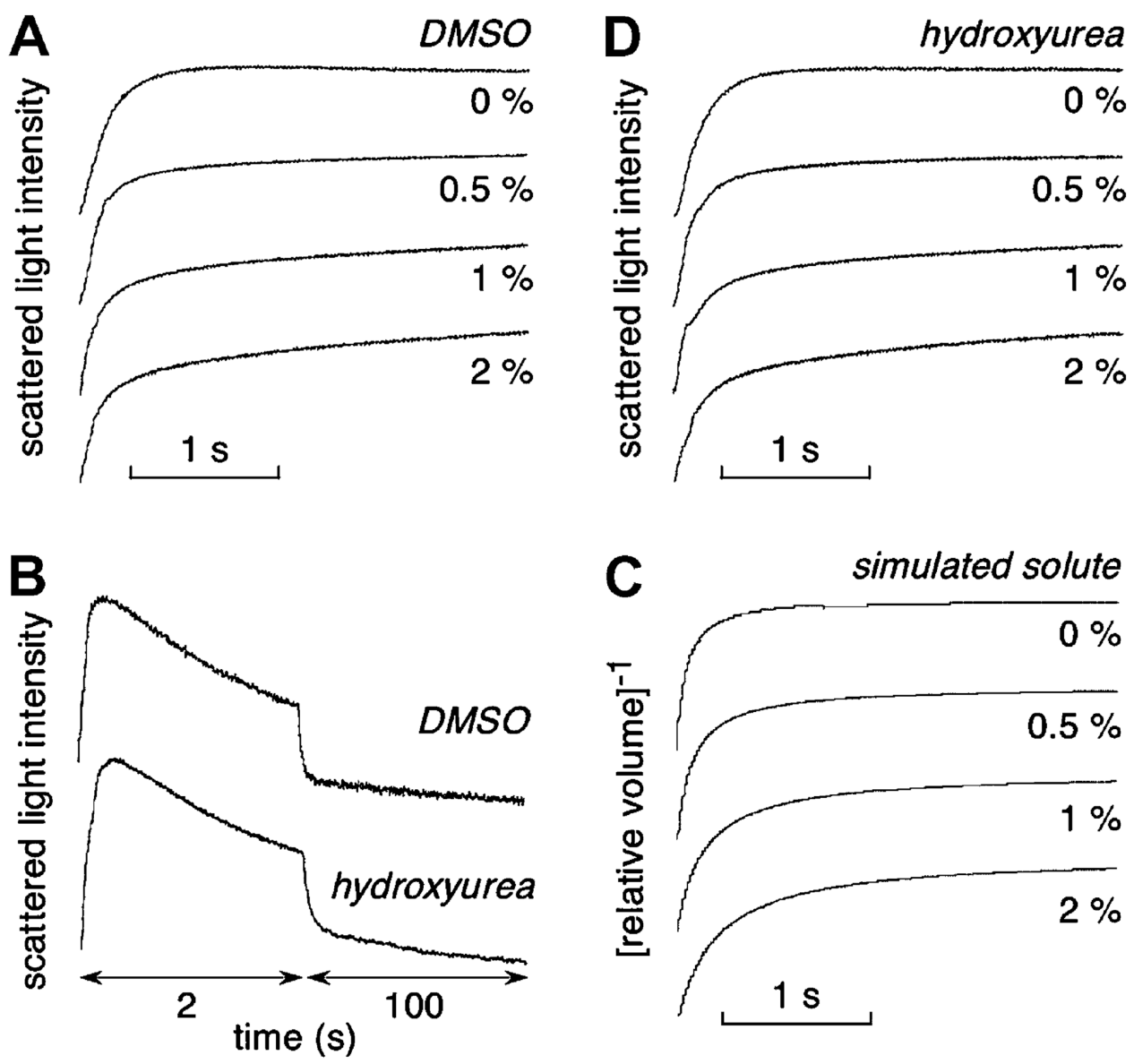

Fig. 5.

Characterization of DMSO slowing of osmotic equilibration. (A) Stopped-flow light scattering measurements of osmotic water permeability in mouse erythrocytes in response to a $250 \mathrm{mM}$ inwardly directed sucrose gradient in the absence or presence of indicated concentrations of DMSO. (B) Measurements of DMSO (top) and hydroxyurea (bottom) permeabilities. Light scattering time course shown in response to a $250 \mathrm{mM}$ inwardly directed gradient of each solute. (C) Predicated erythrocyte volume change for simulations of experiments in (A). Parameters: $P_{\mathrm{f}}=0.025 \mathrm{~cm} / \mathrm{s}, \mathrm{P}_{\mathrm{DMSO}}=1.5 \times 10^{-6} \mathrm{~cm} / \mathrm{s}$. (D) Water transport measurements as in (A) except for replacement of DMSO by hydroxyurea. 